\title{
INVESTIGANDO AS CONCEPÇÕES DE FORÇA EM SITUAÇÕES DO COTIDIANO AO LONGO DO CI- CLO DA EXPERIÊNCIA KELLYANA
}

\author{
Ana Paula Teixeira Bruno Silva \\ Heloisa Flora Brasil Nóbrega Bastos \\ Ernande Barbosa da Costa \\ Departamento de Educação - UFRPE \\ Recife - PE
}

\section{Resumo}

Esta pesquisa teve como objetivo investigar o processo de construção do conceito científico de força entre alunos do $1^{\circ}$ ano do Ensino Médio, que participaram de uma seqüência didática organizada de acordo com as cinco fases do Ciclo da Experiência Kellyana: Antecipação; Investimento; Encontro; Confirmação ou Desconfirmação e Revisão Construtiva. Procurou-se identificar as concepções sobre força em situações do cotidiano. Os resultados desta pesquisa mostraram que os alunos, na fase da Antecipação, possuíam conceitos intuitivos, bem como tinham dificuldades de entender os conceitos de direção e sentido de uma força. As atividades desenvolvidas durante o Ciclo despertaram a atenção dos alunos, impulsionando-os a levantar hipóteses, refletir e estabelecer relações das situações vivenciadas com o tema em estudo, o que oportunizou uma contribuição de forma relevante para a evolução dos seus conceitos.

Palavras-chave: Ensino de Física; Ciclo da Experiência Kellyana; força; cotidiano.

\footnotetext{
${ }^{+}$Investigating the conceptions of force in everyday life situations throughout the Kellyan Experience Cycle

* Recebido: abril de 2007.

Aceito: março de 2008.
} 


\begin{abstract}
This research explored the construction process of the scientific concept of force among pupils at High School, who were engaged in a didactic sequence organized according to the five phases of Kellyan Cycle of experience: Anticipation, Investment, Encounter, Confirmation or Disconfirmation and Constructive Revision. It also intended to identify conceptions of force applied to everyday life situations. The results of this research showed that pupils, during the Anticipation phase, possessed intuitive conceptions as well as difficulties in differentiating the concepts of orientation and direction of a force. The activities developed during the Cycle aroused pupils' attention, impelling them to develop hypotheses, to reflect and to establish relationships between experienced situations and the theme under study. This enabled the evolution of their concepts.
\end{abstract}

Keywords: Physics teaching; Kellyan Cycle of Experience; force; everyday life.

\title{
I. Introdução
}

A Lei de Diretrizes e Bases da Educação Nacional (Lei 9394/96) estabelece uma nova visão para o Ensino Médio, afinada na construção de competências básicas que situem o educando como sujeito produtor de conhecimento e participante do mundo do trabalho e da prática social (BRASIL, 1999). Esse novo paradigma aponta para uma educação que busque condições para que o aluno desenvolva suas potencialidades, capacidades cognitivas, afetivas e sociais, colocando o educador no papel de facilitador da aprendizagem.

As competências de Física não têm significado quando trabalhadas de forma isolada. "Competências em Física para a vida se constroem em um presente contextualizado, em articulação com competências de outras áreas, impregnadas de outros conhecimentos" (BRASIL, 2002, p.59). Nessa perspectiva, o ensino de Física deixa de buscar a transmissão de conteúdos para os alunos e passa a enfatizar o desenvolvimento de competências, que permitam a formação de um aluno cidadão, atuante, interventor e participante na sociedade. 
Visando à implantação desse tipo de educação, neste trabalho foi explorado o conceito de força como uma grandeza vetorial e como causa do movimento dos corpos. Esse conteúdo chama a atenção por ser abordado em diversas instituições de ensino de maneira descontextualizada, desvinculada do dia-a-dia dos alunos. Na prática pedagógica, especialmente entre os alunos do $1^{\circ}$ ano do Ensino Médio, percebem-se certas dificuldades no estudo da Dinâmica, por causa da visão do senso comum e da não compreensão do conceito de força e seus elementos (ponto de aplicação, módulo ou intensidade, direção e sentido). Os mesmos problemas foram detectados por Silva e Silva Filho (2001), em pesquisa realizada com alunos da $1^{\mathrm{a}}$ série do Ensino Médio, utilizando o Princípio da Ação e Reação e na pesquisa de Talim (1999), que mostrou algumas dificuldades de aprendizagem em alunos do Ensino Médio, devidas aos conceitos espontâneos.

Diante desses resultados, percebe-se que, para haver uma mudança conceitual, são necessários procedimentos didáticos que contribuam para a construção do conhecimento. Nesse sentido, este trabalho utilizou como base teórica a Teoria dos Construtos Pessoais - TCP de George Kelly (1963), especificamente o Corolário da Experiência, juntamente com o Ciclo da Experiência e suas cinco fases, que permite analisar como o indivíduo constrói o conhecimento.

\section{A Teoria dos Construtos Pessoais}

Entre as teorias psicológicas, a Teoria dos Construtos Pessoais de George Kelly (1963) fornece um referencial que permite analisar as práticas educacionais. Essa teoria foi fundamentada em um posicionamento filosófico, que Kelly denominou de Alternativismo Construtivo, "as pessoas compreendem a si mesmas, seus arredores e antecipam eventualidades futuras construindo modelos tentativos e avaliando-os em relação a critérios pessoais, quanto à predição com sucesso e controle de eventos baseados nesses modelos" (POPE, 1985 apud BASTOS, 1998, p.1).

Para Kelly (1963), as pessoas, da mesma maneira que os cientistas, desenvolvem teorias para compreender a realidade e antecipar eventos. Desse modo, as teorias de cada indivíduo são vistas como hipóteses abertas à reconstrução (BASTOS, 1992).

Essa teoria tem como objetivo explicar o processo de construção do conhecimento, sendo estruturada em um Postulado Fundamental e onze Corolários, fundamentando-se em duas idéias: a concepção do homem como ser histórico ao longo dos séculos e a valorização do homem como um ser que, ao mesmo tempo 
em que está imerso na corrente dos acontecimentos, contempla-os e interpreta-os (MINGUET, 1998).

O Postulado Fundamental afirma que: "os processos de uma pessoa são psicologicamente canalizados pelas formas como ela antecipa eventos" (KELLY, 1970, p. 9, tradução livre). Isso quer dizer que as pessoas possuem maneiras alternativas de perceber os acontecimentos ao seu redor e de prever eventos futuros. Os onze corolários explicam como as pessoas constroem as réplicas dos eventos que vivenciam, como essas réplicas se estruturam e como elas utilizam esses esquemas mentais para se relacionar com os outros.

O corolário da Experiência afirma que "o sistema de construção de uma pessoa varia quando ela sucessivamente constrói a réplica de eventos" (KELLY, 1970 , p. 17, tradução livre), ou seja, a representação sucessiva de acontecimentos convida o indivíduo à construção de novos processos, sempre que algo inesperado acontece.

\section{Ciclo da Experiência Kellyana}

Uma pessoa aprende, segundo Kelly (1963), quando muda sua estrutura cognitiva após tentar lidar com as situações que ela encontra.

Para Kelly (1963), as experiências constituem a própria aprendizagem. Assim como os cientistas usam a experimentação para testar hipóteses no processo de construção do conhecimento científico, os indivíduos se engajam no Ciclo da Experiência para testar suas hipóteses pessoais e modificá-las quando julgarem necessário. Esse ciclo possui cinco fases, conforme é apresentado na Fig. 1.

As fases do Ciclo da Experiência têm como intuito mostrar como a aprendizagem ocorre nesse processo complexo, iniciando com a fase da Antecipação, em que o indivíduo constrói uma réplica do evento, utilizando os construtos que possui no seu sistema de construção. Após essa fase, o indivíduo se engaja numa fase de Investimento, em que se prepara para encontrar o evento. Nele, o indivíduo compara suas teorias ou hipóteses pessoais, que conduzem à Confirmação ou Desconfirmação das mesmas, seguindo para a Revisão Construtiva dos pontos que geraram problemas (BASTOS, 1998).

Nessa perspectiva, vê-se que esse ciclo de construir os acontecimentos e vê-los confirmados, ou não, contribui para o processo de construção do conhecimento, uma vez que o indivíduo tem a liberdade de reinterpretar o mundo a sua volta. 


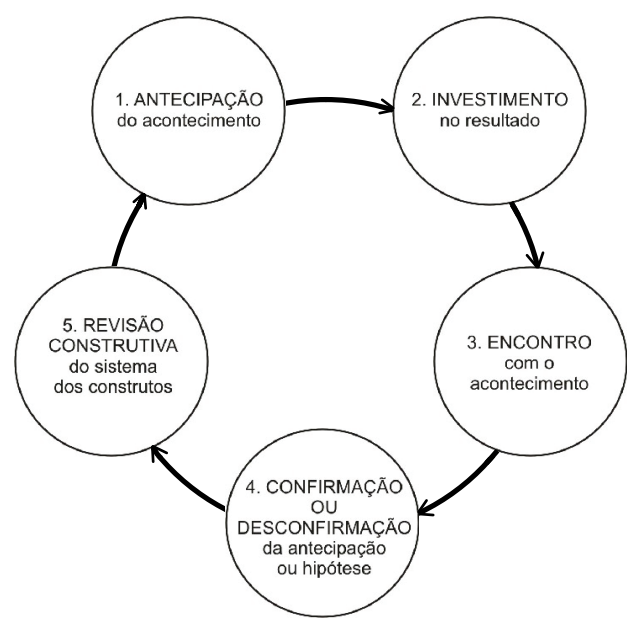

Fig. 1 - As Cinco Fases do Ciclo da Experiência.

Fonte: Adaptado de Cloninger (1999, p. 428).

\section{Forças no cotidiano}

Nas situações do dia-a-dia encontramos forças que podem ser classificadas como de campo e de contato. Dentre essas, temos algumas que são comuns em nossa vida diária, como: força gravitacional, força normal, força de atrito, força de tração e força elástica, que serão apresentadas a seguir:

- Força gravitacional ou força peso $(P)$ : é uma força de campo, resultante da atração gravitacional da Terra sobre os corpos (TIPLER, 1984). Essa atração varia de acordo com a posição do corpo, tanto em relação à latitude e longitude, quanto em relação ao centro da Terra.

- Força normal $\left(F_{n}\right)$ : ocorre devido ao contato entre as superfícies, sendo sua direção perpendicular à superfície de apoio (HEWITT, 2002). Um exemplo prático é quando colocamos um livro sobre uma mesa e ambos trocam forças de contato entre si. Para o livro permanecer em repouso, a resultante das forças que atuam sobre ele deve ser nula, ou seja, a força $F_{n}$ que age no livro "compensa" o seu peso $(P)$, de forma que ele permanece parado.

- Força de atrito $\left(F_{a}\right)$ : ocorre quando duas superfícies deslizam ou tendem a deslizar uma sobre a outra. Essa força reduz a força resultante (força que produz o efeito de todas as forças que agem no corpo) e, consequentemente, a aceleração. $\mathrm{O}$ atrito existe devido às irregularidades nas superfícies de contato e também pode 
ocorrer nos líquidos e gases. Essa força se opõe ao movimento do corpo, sendo chamada de força de atrito estático, quando ocorre tendência ao movimento e força de atrito cinético, quando o corpo está em movimento (HEWITT, 2002).

- Força de tração $(T)$ : força externa ao corpo que provoca um movimento ou tendência para o movimento. Isso pode ser verificado quando um corpo está sendo puxado por uma corda ou fio ligado a ele. Sua direção é ao longo da corda, afastando-se do corpo.

- Força elástica $\left(F_{e l}\right)$ : força aplicada por corpos elásticos, que podem ser representados por uma mola helicoidal, ou que surge no interior de corpos elásticos. Por exemplo, quando um corpo é pendurado a uma mola, a força gravitacional atua sobre ele. A elongação sofrida pela mola é diretamente proporcional à força aplicada. Cessada a aplicação da força, a mola retorna ao comprimento inicial, podendo a intensidade da força ser medida a partir da elongação da mola (HEWITT, 2002).

\section{Metodologia da pesquisa}

A pesquisa foi realizada com 18 alunos do $1^{\mathrm{a}}$ ano do Ensino Médio de uma escola da rede particular, localizada em Olinda - PE, com faixa etária entre 14 e 16 anos. $\mathrm{O}$ trabalho foi estruturado em torno de uma seqüência didática organizada de acordo com as cinco fases do Ciclo da Experiência Kellyana: Antecipação; Investimento; Encontro; Confirmação ou Desconfirmação e Revisão Construtiva. A cada fase do Ciclo foram desenvolvidas algumas atividades, de acordo com o esquema da Fig. 2.

\section{$1^{\mathrm{a}}$ Fase - Antecipação}

O objetivo desta fase foi fazer com que os alunos construíssem réplicas de eventos semelhantes aos que iriam vivenciar, ou seja, que eles lembrassem de aulas, palestras e trabalhos já realizados, de modo que gerassem expectativas, curiosidade, criando suas hipóteses sobre o conceito de força e as aplicações no cotidiano. Iniciou-se a aula com o convite aos alunos para participarem da pesquisa. Em seguida, ocorreu a aplicação do primeiro questionário (ver apêndice) elaborado com seis questões abertas e uma semi-aberta, tendo como objetivo conhecer as concepções prévias dos alunos sobre o tema em estudo. 


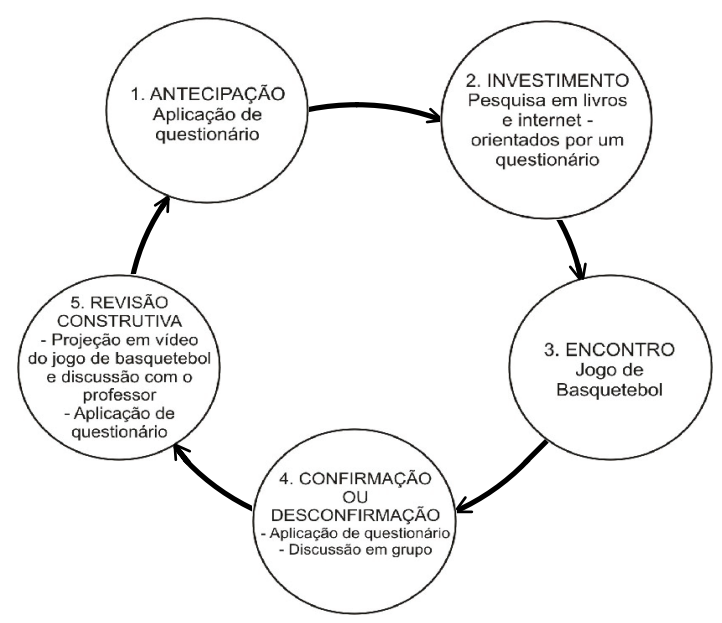

Fig. 2 - Atividades desenvolvidas no CEK.

\section{$2^{\mathrm{a}}$ Fase - Investimento}

Nesta fase, o objetivo foi preparar os alunos para "participarem" do evento, iniciando-se com a solicitação de uma pesquisa na Internet, extraclasse, sobre a definição de força e suas aplicações no dia-a-dia. Essa solicitação foi feita cerca de 15 dias após a primeira fase, na aula de Física da turma. No dia da entrega da pesquisa da Internet, os alunos assistiram à aula na biblioteca da escola, organizados em pequenos grupos. Em seguida, consultaram livros de Física do Ensino Médio Mecânica, e responderam ao segundo questionário (ver apêndice), baseados nas leituras desses livros, nos materiais coletados na Internet e numa discussão do assunto, a fim de chegarem a um consenso.

\section{$3^{\text {a }}$ Fase - Encontro}

Foi o momento do acontecimento, ou seja, o evento, em si, para o qual o aluno foi convidado. O objetivo foi relacionar o conceito de força com suas aplicações no cotidiano. Esta fase ocorreu quinze dias após a fase do Investimento e contou com a participação do professor de Educação Física, que foi convidado para orientar os alunos nas regras do jogo de basquetebol e ser o árbitro das partidas. Em seguida, os alunos foram divididos em quatro equipes e realizaram quatro partidas, com duração de 10 minutos cada, na quadra de esportes da escola. Foi feito um vídeo dessas partidas para ser utilizado como recurso didático na fase da Revisão Construtiva. Após isso, os alunos participaram de uma discussão sobre os 
conceitos científicos de força, suas características e sobre os tipos de forças encontradas no cotidiano.

\section{$4^{\mathrm{a}}$ Fase - Confirmação ou desconfirmação}

Nesta fase, o objetivo foi fazer com que os alunos confirmassem ou rejeitassem as hipóteses construídas na fase da Antecipação e Encontro ou, ainda, que criassem novas hipóteses. Ela ocorreu no mesmo dia, logo após o término do jogo de basquetebol. Os alunos foram para a sala de aula e receberam o primeiro questionário, ao qual haviam respondido na fase da Antecipação, para ler e, em seguida, responder novamente, de forma individual, em outro exemplar do mesmo questionário (em branco), de modo a elaborarem novas respostas, acrescentando ou cancelando o que achassem necessário, baseando-se no que vivenciaram durante as fases do Investimento e do Encontro. Após esse momento, foram formados dois grandes grupos e encaminhados para salas distintas, nas quais fizeram uma discussão sobre as novas respostas dadas ao questionário, em busca de um consenso. Em seguida, os alunos retomaram seus questionários para abandonar ou acrescentar respostas, caso achassem necessário.

\section{$5^{\text {a }}$ Fase - Revisão Construtiva}

Esta fase, cujo objetivo foi fazer com que os alunos revisassem o que foi aprendido, foi dividida em três momentos. O primeiro, com a projeção do vídeo do filme do jogo de basquetebol, durante a qual foram feitas algumas pausas para discutir alguns pontos referentes ao conceito de força, a partir da cena do jogo. $\mathrm{O}$ segundo momento iniciou-se com a análise de algumas jogadas expostas pela professora, com a bola de basquetebol em mãos. Em seguida, foram analisadas as questões do primeiro questionário. Finalmente, no terceiro momento, aplicou-se o terceiro questionário (ver apêndice), que coletou as novas concepções dos alunos, após terem vivenciado todo o Ciclo.

\section{Análise dos resultados}

Nesta seção, iremos analisar apenas algumas respostas dadas aos três questionários aplicados. Devido às dificuldades apresentadas pelos alunos, escolhemos as questões 1 e 5 ( $1^{\circ}$ questionário), 1 ( $2^{\circ}$ questionário), $2 \mathrm{~b}$ e 4 ( $3^{\circ}$ questionário). 
Os quadros 1,2 e 3 apresentam as respostas dos alunos dadas ao $1^{\circ}$ questionário, na $1^{\mathrm{a}}$ fase do Ciclo (Antecipação) e na $4^{\mathrm{a}}$ fase (Confirmação ou Desconfirmação). Dessa forma, podemos analisar as mudanças ocorridas durante a maior parte do Ciclo.

Analisando as respostas dadas pelos alunos na fase da Antecipação, percebe-se que a palavra força aparece relacionada com diversos conceitos como: empurrão, pressão, impulso, energia e resistência. É interessante notar que todos esses conceitos são encontrados no dia-a-dia. Além disso, apesar de não apresentarem o conceito científico de força, as idéias explicitadas são todas ligadas, de formas diferentes, a esse conceito científico. Enquanto na Antecipação 50\% dos alunos possuem a concepção de que a força refere-se a empurrão, na fase da Confirmação ou Desconfirmação $100 \%$ dos alunos relacionaram força à interação entre dois ou mais corpos, demonstrando uma mudança nas suas concepções, aproximando-se do conceito científico.

Observa-se que os alunos A2, A5, A12 e A14, além de relacionarem força à interação entre dois ou mais corpos, acrescentam que ela é uma grandeza vetorial, ressaltando outro aspecto do conceito científico. Nesta fase, percebe-se uma grande evolução, uma vez que, na Antecipação, o aluno A2 relacionou força a impulso, o A5 e A12 à pressão e o A14 a empurrão.

Observa-se, assim, que os alunos, após terem passado pelas fases do Investimento e Encontro, conseguiram modificar seus conceitos, distanciando-se do senso comum. Além disso, verifica-se que a variação no sistema de construção dos alunos, no que diz respeito à idéia de força, foi bastante significativa, uma vez que se aproximaram do conceito científico.

Os resultados obtidos na questão 5 ( $1^{\circ}$ questionário) serão apresentados, parcialmente, nos quadros distintos 2 e 3 (direção e sentido, respectivamente).

$\mathrm{Na}$ fase da Antecipação, com relação à direção da força, os alunos demonstraram pouca compreensão, apresentando características do sentido e outras respostas, em vez de características da direção (apenas A1 indicou uma característica da direção). Enquanto isso, na fase da Confirmação ou Desconfirmação, apenas um aluno A9, continuou indicando uma característica do sentido e outro aluno (A10) referiu-se à trajetória da bola. Os demais indicaram características da direção, apesar de um grupo maior $(77,7 \%)$ ter respondido que a direção era horizontal, sugerindo uma possível associação entre a direção da força e a direção da reta que liga (no desenho) a bola à cesta, como indicam as respostas dos alunos A5, A14, A15 e A16 na Antecipação. Assim, apesar desses alunos terem dado uma resposta errada, eles não estão mais confundindo direção e sentido. É interessante 
observar que os alunos A1 e A6 apresentaram respostas distintas do restante do grupo (e corretas!), mesmo tendo participado das diversas discussões. Esse resultado mostra a força do grupo, que convergiu para uma resposta comum, ao mesmo tempo em que também indica a existência de pessoas que não se deixam influenciar pelos debates (A9 e A10) e outras que mudam de perspectiva e se apegam a ela, apesar do posicionamento do grupo.

Quadro 1 - Categorização das respostas referentes à questão 1 ( $1^{\circ}$ questionário).

\begin{tabular}{|c|c|c|c|c|c|c|}
\hline \multirow{2}{*}{$\begin{array}{l}\text { CATEGORIAS } \\
\text { DAS } \\
\text { RESPOSTAS }\end{array}$} & \multicolumn{3}{|c|}{ ANTECIPAÇÃO } & \multicolumn{3}{|c|}{$\begin{array}{l}\text { CONFIRMAÇÃO OU } \\
\text { DESCONFIRMAÇÃO }\end{array}$} \\
\hline & ALUNOS & FR & $\%$ & ALUNOS & FR & $\%$ \\
\hline Empurrão & $\begin{array}{c}\text { A3,A6,A7, } \\
\text { A8,A9,A11, } \\
\text { A13,A14,A18 }\end{array}$ & 9 & 50,0 & - & - & - \\
\hline Pressão & $\mathrm{A} 5, \mathrm{~A} 12, \mathrm{~A} 15$ & 3 & 16,7 & - & - & - \\
\hline Impulso & $\mathrm{A} 1, \mathrm{~A} 2, \mathrm{~A} 4$ & 3 & 16,7 & - & - & - \\
\hline Energia & A16,A17 & 2 & 11,1 & - & - & - \\
\hline Resistência & A 10 & 1 & 5,6 & - & - & - \\
\hline $\begin{array}{l}\text { Interação durante } \\
\text { o contato entre } \\
\text { dois ou mais } \\
\text { corpos em movi- } \\
\text { mento. }\end{array}$ & - & - & - & $\begin{array}{l}\mathrm{A} 1, \mathrm{~A} 3, \mathrm{~A} 7, \mathrm{~A} 8 \\
\mathrm{~A} 13, \mathrm{~A} 15, \mathrm{~A} 18\end{array}$ & 7 & 38,9 \\
\hline $\begin{array}{l}\text { Interação entre } \\
\text { dois ou mais } \\
\text { corpos. }\end{array}$ & - & - & - & $\begin{array}{l}\text { A4,A6,A9, } \\
\text { A10,A11, } \\
\text { A16,A17 } \\
\end{array}$ & 7 & 38,9 \\
\hline $\begin{array}{l}\text { Grandeza vetorial } \\
\text { - interação entre } \\
\text { dois ou mais } \\
\text { corpos. }\end{array}$ & - & - & - & $\begin{array}{c}\text { A2,A5, } \\
\text { A12,A14 }\end{array}$ & 4 & 22,2 \\
\hline TOTAL & - & 18 & 100,0 & - & 18 & 100,0 \\
\hline
\end{tabular}

FR - Freqüências das respostas

Fonte: SILVA, 2007, p.50. 
Quadro 2 - Respostas dadas à questão 5 - direção ( $1^{\circ}$ questionário).

\begin{tabular}{|c|c|c|c|c|c|c|}
\hline \multirow{2}{*}{$\begin{array}{c}\text { CATEGORIAS } \\
\text { DAS } \\
\text { RESPOSTAS }\end{array}$} & \multicolumn{3}{|c|}{ ANTECIPAÇÃO } & \multicolumn{3}{|c|}{$\begin{array}{l}\text { CONFIRMAÇÃO OU } \\
\text { DESCONFIRMAÇÃO }\end{array}$} \\
\hline & ALUNOS & FR & $\%$ & ALUNOS & FR & $\%$ \\
\hline Horizontal & A1 & 1 & 5,6 & $\begin{array}{c}\mathrm{A} 2, \mathrm{~A} 3, \mathrm{~A} \\
4, \\
\mathrm{~A} 5, \mathrm{~A} 7, \mathrm{~A} \\
8, \\
\mathrm{~A} 11, \mathrm{~A} 12, \\
\mathrm{~A} 13, \mathrm{~A} 14, \\
\mathrm{~A} 15, \mathrm{~A} 16, \\
\mathrm{~A} 17, \mathrm{~A} 18\end{array}$ & 14 & 77,7 \\
\hline Direita & $\begin{array}{l}\text { A3,A4, } \\
\text { A7,A16 }\end{array}$ & 4 & 22,2 & - & - & - \\
\hline Cesta & $\begin{array}{l}\text { A5,A14, } \\
\text { A15,A18 }\end{array}$ & 4 & 22,2 & - & - & - \\
\hline Para frente & $\begin{array}{c}\text { A6,A9, } \\
\text { A12,A13 }\end{array}$ & 4 & 22,2 & A9 & 1 & 5,6 \\
\hline $\begin{array}{l}\text { Trajetória da } \\
\text { bola }\end{array}$ & A10,A11 & 2 & 11,1 & A 10 & 1 & 5,6 \\
\hline Inclinada & - & - & - & $\mathrm{A} 1, \mathrm{~A} 6$ & 2 & 11,1 \\
\hline Não respondeu & $\begin{array}{l}\text { A2,A8, } \\
\text { A17 }\end{array}$ & 3 & 16,7 & - & - & - \\
\hline TOTAL & - & 18 & 100,0 & - & 18 & 100,0 \\
\hline
\end{tabular}

FR - Freqüências das respostas

Fonte: SILVA, 2007, p. 59.

Nesse quadro, também se observou, na fase da Antecipação, a confusão entre os conceitos de direção e sentido. Dessa forma, 33,4\% dos alunos (A1, A3, A7, A12, A13 e A16) apresentaram aspectos ligados à direção. Além desse percentual, 33,3\% dos alunos deram respostas referentes a outros conceitos, como a trajetória da bola e a cesta. Apenas 16,7\% apresentaram características relativas ao sentido, como: para frente (alunos A4 e A5) e oposto (aluno A6), sendo que apenas os alunos A4 e A5 (11,1\%) deram a resposta correta. 
Quadro 3 - Respostas dadas à questão 5 - sentido ( $1^{\circ}$ questionário).

\begin{tabular}{|c|c|c|c|c|c|c|}
\hline \multirow{2}{*}{$\begin{array}{c}\text { CATEGORIAS } \\
\text { DAS } \\
\text { RESPOSTAS }\end{array}$} & \multicolumn{3}{|c|}{ ANTECIPAÇÃO } & \multicolumn{3}{|c|}{$\begin{array}{l}\text { CONFIRMAÇÃO OU } \\
\text { DESCONFIRMAÇÃO }\end{array}$} \\
\hline & ALUNOS & FR & $\%$ & ALUNOS & FR & $\%$ \\
\hline Horizontal & $\begin{array}{c}\text { A3,A7, } \\
\text { A12,A16 }\end{array}$ & 4 & 22,2 & - & - & - \\
\hline Trajetória da bola & $\begin{array}{l}\text { A9,A14, } \\
\text { A15,A18 }\end{array}$ & 4 & 22,2 & A10 & 1 & 5,6 \\
\hline Para frente & A4,A5 & 2 & 11,1 & $\begin{array}{l}\text { A2,A4,A5, } \\
\text { A6,A9,A11,A } \\
13, \mathrm{~A} 14, \mathrm{~A} 15\end{array}$ & 9 & 50,0 \\
\hline Cesta & $\mathrm{A} 10, \mathrm{~A} 11$ & 2 & 11,1 & - & - & - \\
\hline Vertical & A13 & 1 & 5,6 & - & - & - \\
\hline Oposto & A6 & 1 & 5,6 & - & - & - \\
\hline Direita & A1 & 1 & 5,6 & $\begin{array}{l}\text { A7,A12, } \\
\text { A16 }\end{array}$ & 3 & 16,7 \\
\hline Inclinado & - & - & - & $\begin{array}{c}\text { A3,A8, } \\
\text { A17,A18 }\end{array}$ & 4 & 22,2 \\
\hline Para cima & - & - & - & A1 & 1 & 5,6 \\
\hline Não respondeu & $\begin{array}{l}\text { A2,A8, } \\
\text { A17 }\end{array}$ & 3 & 16,7 & - & - & - \\
\hline TOTAL & - & 18 & 100,0 & - & 18 & 100,0 \\
\hline
\end{tabular}

FR - Freqüências das respostas

Fonte: SILVA, 2007, p. 61.

Na fase da Confirmação ou Desconfirmação $50 \%$ dos alunos (A2, A4, A5, A6, A9, A11, A13, A14 e A15) apresentaram a resposta correta, enquanto $22,2 \%$ dos alunos (A3, A8, A17 e A18) apresentaram aspectos da direção em vez do sentido, 22,3\% dos alunos (A1, A7, A12 e A16) aspectos do sentido, mas que não correspondiam à situação exposta e 5,6\% dos alunos (A10) a outro conceito, como a trajetória da bola. 
Diante desse quadro, observou-se que, mesmo com $50 \%$ de acertos, os conceitos de direção e sentido precisam ser trabalhados de maneira especial pelos professores, durante as aulas, para que haja uma compreensão por parte dos alunos.

O quadro 4 apresenta as respostas referentes à questão 1 ( $2^{\circ}$ questionário), aplicado na fase do Investimento, em que os alunos foram organizados nos seguintes grupos:

- GRUPO 1 - alunos 3 e 11

- GRUPO 2 - alunos 6 e 15

- GRUPO 3 - alunos 1, 4, 5 e 12

- GRUPO 4 - alunos $8,13,17$ e 18

- GRUPO 5 - alunos 2, 7, 9, 10, 14 e 16

As respostas dadas pelos grupos à questão foram enquadradas em mais de uma categoria. 31,8\% dos alunos responderam que força é interação entre dois ou mais corpos, como foi apresentado pelos materiais da Internet e pelos livros, sendo a definição que prevaleceu para todos os alunos na fase da Confirmação ou Desconfirmação, no quadro 1 .

O grupo 1 fez também referência à força como sendo agente fisico, com a capacidade de modificar um corpo. É interessante notar que nessa definição os alunos não explicitaram o tipo de capacidade, deixando margem para várias interpretações. Supõe-se que essa capacidade esteja relacionada à deformação de um corpo e à mudança de velocidade. Os alunos do grupo 2 detiveram-se apenas na interação entre dois ou mais corpos, não apresentando a maneira como essa interação pode acontecer: por campo ou contato. $\mathrm{O}$ grupo 3 acrescentou que um corpo jamais sairá do repouso sem a ação de uma força, apresentando informações do material da Internet. Observa-se que os alunos praticamente não reelaboraram o texto, limitando-se a recortar os trechos que interessavam, indicando falta de uma maior reflexão sobre as idéias que estão contidas no mesmo. O grupo 4 acrescentou mais duas definições à força: grandeza vetorial caracterizada pela intensidade, direção e sentido e agente fisico cujo efeito dinâmico é a aceleração. Verificase que esse grupo apresentou também recortes do material da Internet, quando se referiram à grandeza vetorial e à definição de força apresentada pelo livro Doca et al. (2001). O grupo 5 acrescentou mais duas informações sobre a definição de força. Verifica-se que esse grupo apresentou informações que permeiam o conceito científico de força. No entanto, estas foram mostradas em partes, sem relação de uma com a outra. 
Quadro 4 - Categorização das respostas referentes à questão 1 (2º questionário).

\begin{tabular}{|l|c|c|c|}
\hline \multicolumn{1}{|c|}{$\begin{array}{c}\text { CATEGORIAS } \\
\text { DAS } \\
\text { RESPOSTAS }\end{array}$} & ALUNOS & FR & $\%$ \\
\hline $\begin{array}{l}\text { Interação entre dois ou mais corpos. } \\
\text { A1,A2,A3,A4,A5, } \\
\text { A6,A7,A9,A10,A11, } \\
\text { A12,A14,A15,A16 }\end{array}$ & 14 & 31,8 \\
\hline $\begin{array}{l}\text { Um corpo jamais sairá do repouso } \\
\text { sem a ação de uma força. }\end{array}$ & $\begin{array}{c}\text { A1,A4,A5,A8, } \\
\text { A12,A13,A17,A18 }\end{array}$ & 8 & 18,2 \\
\hline $\begin{array}{l}\text { Um corpo não exerce força sobre si } \\
\text { mesmo. }\end{array}$ & $\begin{array}{c}\text { A2,A7,A9, } \\
\text { A10,A14,A16 }\end{array}$ & 6 & 13,6 \\
\hline $\begin{array}{l}\text { Ação capaz de colocar um corpo em } \\
\text { movimento, de modificar o movi- } \\
\text { mento e deformar um corpo. }\end{array}$ & A2,A7,A9, & 6 & 13,6 \\
\hline $\begin{array}{l}\text { Grandeza vetorial caracterizada pela } \\
\text { intensidade, direção e sentido. }\end{array}$ & A10,A14,A16 & 44 & 00,0 \\
\hline $\begin{array}{l}\text { Agente físico, cujo efeito dinâmico é } \\
\text { a aceleração. }\end{array}$ & A8,A13,A17,A18 & 4 & 9,1 \\
\hline $\begin{array}{l}\text { Agente físico com capacidade de } \\
\text { modificar um corpo. }\end{array}$ & A8,A13,A17,A18 & 4 & 9,1 \\
\hline $\begin{array}{l}\text { TOTAL } \\
\text { A3,A11 }\end{array}$ & & \\
\hline
\end{tabular}

FR - Freqüências das respostas

Fonte: SILVA, 2007, p. 79.

Durante essa fase do Ciclo, os alunos tiveram a oportunidade de pesquisar, ler, discutir, e refletir sobre a definição de força apresentada nos materiais. No entanto, verificou-se uma deficiência com relação à leitura e reelaboração dos textos, requerendo uma atenção especial do professor na utilização de atividades que proporcionem o desenvolvimento dessas competências, que são propostas pelos PCN (BRASIL, 1999) e os PCN ${ }^{+}$(BRASIL, 2002). 
Os quadros 5, 6 e 7 apresentam as respostas referentes às questões $2 \mathrm{~b}$ e 4 ( $3^{\circ}$ questionário), na $5^{\mathrm{a}}$ fase do Ciclo (Revisão Construtiva). Dessa forma, podemos analisar as mudanças ocorridas após as cinco fases do Ciclo.

Quadro 5 - Respostas dadas à questão $2 \mathrm{~b}$ - direção ( $3^{\circ}$ questionário).

\begin{tabular}{|c|c|c|c|}
\hline $\begin{array}{c}\text { CATEGORIAS } \\
\text { DAS } \\
\text { RESPOSTAS }\end{array}$ & ALUNOS & FR & $\%$ \\
\hline Vertical & $\begin{array}{c}\text { A1,A2,A3,A4,A5, } \\
\text { A6,A7,A8,A10, } \\
\text { A11,A12,A13,A14, } \\
\text { A15,A16,A17,A18 }\end{array}$ & 17 & \\
\hline Para baixo & A9 & 1 & 94,4 \\
\hline TOTAL & - & 18 & 5,6 \\
\hline
\end{tabular}

FR - Freqüências das respostas

Fonte: SILVA, 2007, p. 91.

Percebe-se, no quadro 5, que 94,4\% dos alunos indicaram a direção correta, o que evidencia entendimento do conceito. Apenas o aluno A9 apresentou aspecto do sentido ao invés da direção. Observa-se, assim, que as concepções de todos os alunos, com exceção do aluno A9, evoluíram no sentido de se aproximar do conceito científico, o que evidencia o quanto a vivência nas fases da Antecipação; Investimento; Encontro; Confirmação ou Desconfirmação contribuíram para essa evolução. Os resultados apresentados nos quadros 2 e 3 mostram como eram as idéias dos alunos antes da fase da Revisão Construtiva, em relação a esse conceito, ratificando essa evolução.

No quadro 6, continua-se observando que todos os alunos, com exceção do aluno A9, acertaram a questão. Esse resultado positivo indica que os alunos conseguiram indicar a característica do sentido ao invés da direção. 
Quadro 6 - Respostas dadas à questão $2 \mathrm{~b}$ - sentido ( $3^{\circ}$ questionário).

\begin{tabular}{|c|c|c|c|}
\hline $\begin{array}{c}\text { CATEGORIAS } \\
\text { DAS } \\
\text { RESPOSTAS }\end{array}$ & ALUNOS & FR & $\%$ \\
\hline Para baixo & $\begin{array}{c}\text { A1,A2,A3,A4, } \\
\text { A5,A6,A7,A8,A10, } \\
\text { A11, A12,A13,A14, } \\
\text { A15,A16,A17,A18 }\end{array}$ & 17 & 94,4 \\
\hline Vertical & A9 & 1 & 5,6 \\
\hline TOTAL & - & 18 & 100,0 \\
\hline
\end{tabular}

FR - Freqüências das respostas

SILVA, 2007, p. 92.

Diante desses resultados, percebe-se mais uma vez que, a cada fase do Ciclo, o aluno vai organizando suas idéias, aproximando-se do conceito científico. Nesse sentido, percebe-se que o Ciclo contribuiu nessa evolução, embora alguns alunos não tenham atingido o patamar desejado. Acredita-se que esses alunos não tenham participado de maneira satisfatória da seqüência de atividades apresentadas, não demonstrando alterações significativas em suas concepções prévias. Segundo Kelly (1963), essas alterações poderiam ocorrer com a repetição da experiência.

No quadro 7, verifica-se que, dos 18 alunos que participaram desta pesquisa, 11 responderam corretamente (alunos A2, A3, A4, A5, A9, A10, A11, A12, A14, A15 e A16), explicitando as forças peso e elástica, que atuam no rapaz. Esse resultado mostra-se interessante, uma vez que a maioria dos alunos conseguiu responder corretamente. Esse resultado positivo pode ter sido devido às discussões na segunda atividade da fase da Revisão Construtiva, na análise da questão $7 \mathrm{~b}\left(1^{\circ}\right.$ questionário). $\mathrm{O}$ aluno A12 indicou, além das forças peso e elástica as forças de tração e normal, que não se aplicam a essa situação. Observa-se, portanto, que esse aluno tentou utilizar todas as forças vivenciadas nas diversas fases do Ciclo. 
Quadro 7 - Categorização das respostas referentes à questão 4 ( $3^{\circ}$ questionário).

\begin{tabular}{|c|c|c|c|}
\hline $\begin{array}{c}\text { CATEGORIAS } \\
\text { DAS } \\
\text { RESPOSTAS }\end{array}$ & ALUNOS & FR & $\%$ \\
\hline Força peso e elástica & $\begin{array}{c}\text { A2,A3,A4,A5,A9,A10, } \\
\text { A11,A12,A14,A15,A16 }\end{array}$ & 11 & 47,8 \\
\hline Força elástica & A7,A8,A13,A18 & 4 & 17,4 \\
\hline Força de tração & A1,A7,A12,A17 & 4 & 17,4 \\
\hline Força normal & & & \\
\hline Força peso & A1,A12 & 2 & 8,7 \\
\hline Não respondeu & A1 & 1 & 4,3 \\
\hline TOTAL & A6 & 1 & 4,3 \\
\hline
\end{tabular}

FR - Freqüências das respostas

Fonte: SILVA, 2007, p. 99.

Os alunos A7, A8, A13 e A18 só conseguiram identificar na situação a força elástica; não indicando a força peso. Entretanto, esses alunos perceberam a atuação da força peso na questão 3 desse mesmo questionário, o que evidencia que esses alunos precisam rediscutir esse conceito.

A resposta apresentada pelo aluno A1 explicita três forças: peso (que ocorre na situação), tração e normal. Quanto à força de tração, acredita-se que o mesmo não estava atento ao tipo de fio (elástico) que sustentava o rapaz, indicando força de tração ao invés de força elástica. Já a força normal, que não é aplicada à situação, pode ter sido uma tentativa de utilizar os tipos de força discutidos nas atividades. O aluno A6 foi o único que não conseguiu identificar nenhum tipo de força, não respondendo à questão.

De acordo com esses resultados, percebe-se que a maioria dos alunos evoluiu, aplicando o conceito científico. Além disso, verificou-se um processo de 
fragmentação das idéias, compatível com o Corolário da Fragmentação proposto por Kelly (1963), para os alunos (A7, A13 e A18) que não identificaram a força elástica. Não obstante, acredita-se que os resultados sirvam de orientação para os professores de Física do Ensino Médio, proporcionando-lhes subsídios para que organizem atividades, viabilizando contextos diversos em que apareçam diferentes combinações de forças.

\section{Conclusões}

Considerando-se todos os resultados apresentados, baseados nas teorias discutidas anteriormente, conclui-se que:

- Com relação à seqüência didática organizada de acordo com o Ciclo da Experiência Kellyana, observou-se que possibilitou aos alunos manifestarem suas idéias prévias, trabalhar em grupo, pesquisar, ler, discutir e refletir, que são procedimentos sugeridos pelos PCN (BRASIL, 1999), $\mathrm{PCN}^{+}$(BRASIL, 2002) e as OCEM (BRASIL, 2006). Além disso, contribuiu para a aprendizagem, uma vez que as concepções dos alunos a respeito da força e suas aplicações no cotidiano evoluíram, aproximando-se do conceito científico.

- A maioria dos alunos passou a distinguir de forma bastante evidente as características da força: ponto de aplicação, intensidade, direção e sentido, que na fase da Antecipação do Ciclo da Experiência Kellyana, foram identificados como conceitos confusos.

- O jogo de basquetebol, ocorrido na fase do Encontro, viabilizou aos alunos vivenciar uma situação do cotidiano, em que puderam refletir sobre suas concepções iniciais, comparando-as com as cientificamente aceitas.

- As cinco fases do Ciclo da Experiência Kellyana: Antecipação; Investimento; Encontro; Confirmação ou Desconfirmação e Revisão Construtiva proporcionaram aos alunos a experiência que, segundo Kelly (1963), constitui a própria aprendizagem. Para Kelly, a cada evento que o indivíduo vivencia, ele altera seu processo de construção. Essa alteração no sistema de construção de um indivíduo ocorre devido à nova interpretação de um mesmo evento, como indica o Corolário da Experiência.

- Este estudo sugere a viabilidade de uma prática de ensino voltada para a construção de conceitos científicos, não só de força, mas de outros conceitos físicos, químicos ou biológicos que os professores queiram trabalhar. 


\section{Referências}

BASTOS, H. F. B. N. Changing teachers' practice: towards a constructivist methodology of physics teaching. 1992. Thesis (PhD) - University of Surrey, Inglaterra.

A teoria do construto pessoal. Recife: UFRPE - Departamento de Educação, 1998.

BRASIL, Ministério da Educação, Secretaria de Educação Média e Tecnológica. Parâmetros curriculares nacionais: Ensino Médio. Brasília: Ministério da Educação, 1999.

Ministério da Educação, Secretaria de Educação Média e Tecnológica. PCN+ Ensino Médio: orientações educacionais complementares aos parâmetros curriculares nacionais. Brasília: MEC,SEMTEC, 2002.

, Ministério da Educação, Secretaria de Educação Média e Tecnológica. Orientações curriculares para o ensino médio. Brasília: MEC, SEMTEC, 2006.

CLONINGER, S. C. Teorias da personalidade. São Paulo: Martins Fontes, 1999.

DOCA, R. H.; BISCUOLA, G. J.; BÔAS, N. V.. Tópicos de Física 1. 18. ed. São Paulo: Saraiva, 2001.

HEWITT, P. G. Física conceitual. 9 ed. Porto Alegre: Bookman, 2002.

KELLY, G. A. A theory of personality: the psychology of personal constructs. New York: Norton, 1963.

A brief introduction to personal construct theory. In: BANNISTER, D.

(Ed.). Perspectives in personal construct theory. London: Academic Press, 1970.

SERWAY, R. A. Princípios de Física. São Paulo: Pioneira Thomson Learning, 2005. v. 1.

SILVA, A. P. T. B. Investigando as concepções sobre força durante o ciclo da experiência kellyana. 2007. Dissertação (Mestrado em Ensino das Ciências) UFRPE. 
SILVA, A. P. T. B.; SILVA FILHO, A. J. Construindo competências no Ensino Médio: uma abordagem utilizando a $3^{\mathrm{a}}$ lei de Newton com alunos da $1^{\mathrm{a}}$ série. 2001. Monografia (Especialização) - Universidade Federal de Pernambuco, Recife.

TALIM, S. L. Dificuldades de aprendizagem na terceira lei de Newton. Caderno Catarinense de Ensino de Física, Florianópolis, v. 16, n. 2, 1999, p. 143-153.

TIPLER, P. A. Física. 2. ed. Rio de Janeiro: Guanabara Dois, 1984. v. 1.

\section{Questionários aplicados nas fases do ciclo da experiência kellyana}

\section{(1ºuestionário) Fase da antecipação e confirmação ou desconfirmação}

1- Expresse com suas palavras o que você entende por força.

2- Para você, existe relação entre força e movimento? Justifique.

3- Uma força pode ser representada graficamente? Como?

4- O que é necessário para identificar uma força?

5- Numa partida de basquete, o pivô apoiou a mão espalmada atrás da bola e a impulsionou violentamente, mirando a cesta. A bola atravessou a quadra e caiu na cesta do adversário, garantindo à equipe três pontos decisivos. Identifique no desenho os elementos (ponto de aplicação, direção e sentido) da força de lançamento descritos no caso citado.

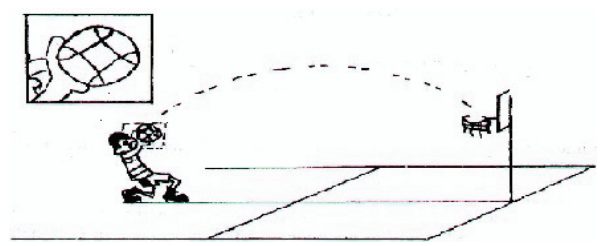

6- Dois rapazes estão puxando, com uma corda, um barco de pesca para a margem do rio. Em qual das situações abaixo, os rapazes conseguiriam trazer o barco mais rápido para a margem do rio? Justifique.

I) ( )

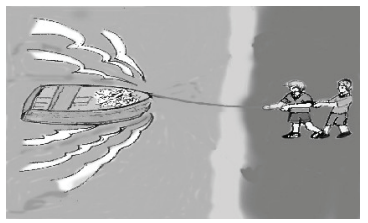

II) $(\quad)$

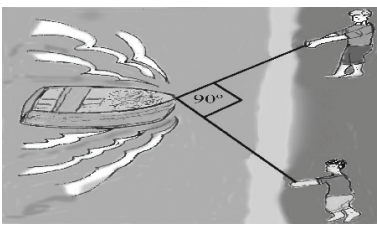


Justificativa:

7- Analise as situações abaixo e determine a direção e o sentido da força aplicada:

a) Dois rapazes empurrando o carro numa avenida.

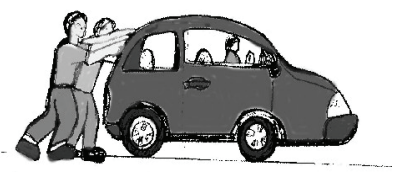

Direção:

Sentido:

b) Um carro comprimindo uma mola.

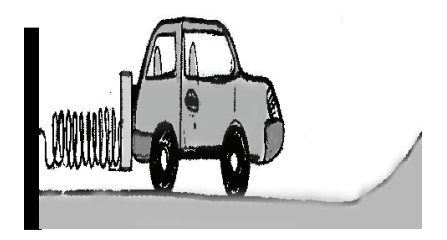

Direção:

Sentido:

c) Um menino puxando a corrente do cachorro.

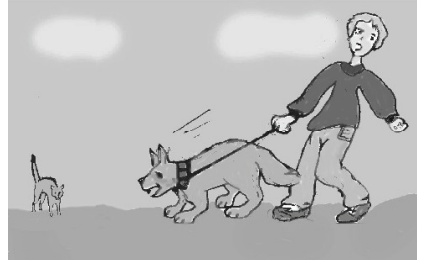

Direção:

Sentido:

\section{( $2^{\circ}$ questionário) Fase do investimento}

Após pesquisar na Internet e em livros de Física do Ensino Médio, responda às questões abaixo:

1- Como você define força?

2- Como podemos representar uma força?

3- Quais as características de uma força?

4- Quais os efeitos de uma força?

5-O número total de forças no universo, em um determinado instante é ímpar ou par? Justifique. 


\section{$\left(3^{\circ}\right.$ questionário) Fase da revisão construtiva}

1- Expresse com suas palavras o que você entende por força.

2- Numa partida de basquetebol, os jogadores no momento do jogo fazem vários passes e dribles. Identifique nos desenhos abaixo, a direção e o sentido da força aplicada à bola.

a)

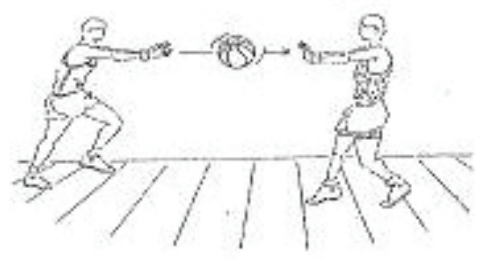

Direção:

Sentido:

b)

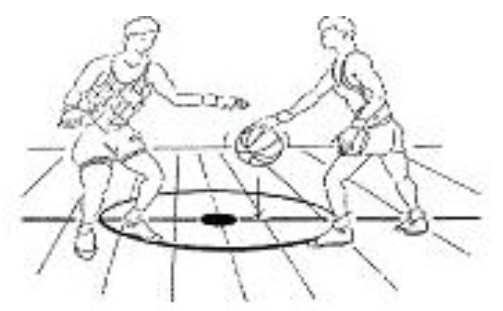

Direção:

Sentido:

c)

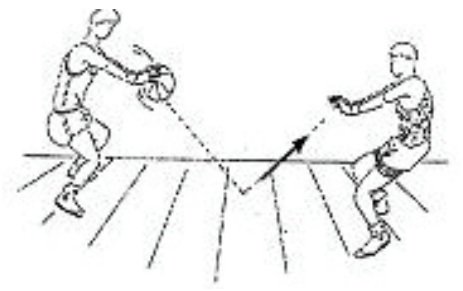

Direção:

Sentido:

3- No arremesso da bola para a cesta no jogo de basquetebol, qual(is) força(s) estão atuando na bola, nos dois casos abaixo?

a)

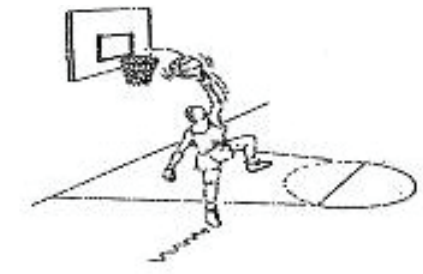

b)

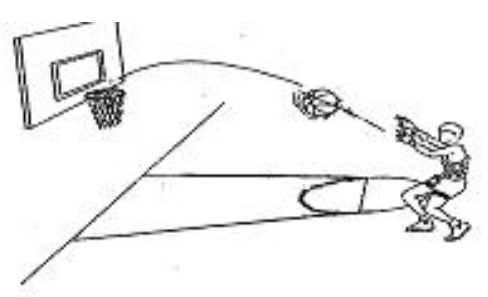


4- No Bungee Jumping, de acordo com a figura, quais as forças que estão atuando no rapaz?

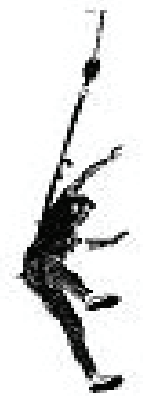

Bungee Jumping: salto com elástico

5- Quando o nadador aplica a força de seu braço para trás em oposição à água em uma piscina, qual o corpo que exerceu a força de ação e qual exerceu a força de reação?

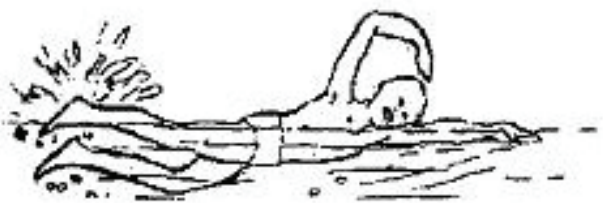

